\title{
Removal of nonyl phenol ethoxylates in water by catalytic ozonation in presence of silica supported - cobalt nanoparticles
}

- Trong Tri Tran-Truong

- Mai My Thi Nguyen

- Hanh Nguyen-Ngoc - Email: nnhanh@hcmut.edu.vn

- Thao Vo-Huu

Ho Chi Minh City University of Technology, VNU-HCM

(Manuscript Received on July, 2016, Manuscript Revised on September, 2016)

\section{ABSTRACT}

The catalytic ozonation of nonionic surfactant nonylphenolethoxylate (NPE) as pollutant in wastewater and its degradation in the presence of silica-supported Cobalt oxide nanoparticles was studied. Characterization of silica supported-cobalt oxide was made using $X R D$ patterns and SEM profiles. The influence of $p H$, initial NPE concentration, ozonation time

and catalyst contents in ozonation process was also investigated. Results show that NPE removals by using silica supported-cobalt oxide catalytic systems are higher than that of using single ozonation. About 99\% NPE were removed within 10 min at $30^{\circ} \mathrm{C}$. Furthermore, in this condition more than $50 \%$ of total carbon of NPE was mineralized.

Keywords: nonyl phenol ethoxylate, catalyst, ozonation, $\mathrm{Co}_{3} \mathrm{O}_{4}$, mineralisation

\section{INTRODUCTION}

Nonyl phenol Ethoxylates (NPEs) are nonionic surfactants belongs to alkyl phenol ethoxylates family having structure as following:

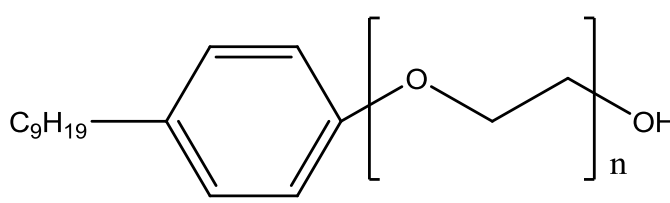

Commercial NPEs has $\mathrm{n}$ value being from 2 to 16. They are widely used in industrial production such as agriculture, leather, metal, petroleum, pulp and paper, paints, adhesives, coatings, cleaners...NPEs decomposes in strong bases, strong acids or strong oxidizing agents. The shorter length of ethoxylate chain, the more toxic NPEs are. The decomposition of NPE could produce hydrophobic NP, NP1EO, NP2EO having smaller biodegradation rate [1-2] and the carboxylic acid nonylphenols (NP2EC or NP1EC), NPEO having toxicity higher NPE.

Among the methods for treating NPE and other pollutants, ozonation and other advanced oxidation processes (AOPs) are paid more attention since they are "environmental friendly". Based on hydroxyl-free radicals $(* \mathrm{OH})$ 
which are immediately generated during the reaction they can decompose the compounds into reaction products with less toxicological effect rather than simply separating them from the flow (such as adsorption or membrane processes). Ozonation is often applied in oxidation processes thanks to its advantages among other common oxidation agents. The oxidizing agent creates the hydroxyl radicals ( ${ }^{*} \mathrm{OHs}$ ) such as $\mathrm{H}_{2} \mathrm{O}_{2}, \mathrm{O}_{3} \ldots$ which will continue take part in intermediate chain reactions.

Additionally, some results have suggested that the surface reactive oxygen species in heterogeneous catalysts might also play an important role in catalytic ozonation of ibuprofen, sodium dodecyl sulfonate...[3,4,5,6]. Many metallic oxides as catalysts could afford this property such as $\mathrm{Fe}_{2} \mathrm{O}_{3}, \mathrm{Al}_{2} \mathrm{O}_{3}, \mathrm{MnO}_{2}$, $\mathrm{Ru} / \mathrm{CeO}_{2}, \mathrm{TiO}_{2}, \mathrm{Fe}^{2+}, \mathrm{Fe}^{3+}, \mathrm{Mn}^{2+}, \ldots$. Some porous materials like silica, activated carbon have been used as adsorbents or catalyst supports. They are effective for the ozonation process in increasing the production of free ${ }^{*} \mathrm{OH}$ radicals in aqueous solution and adsorbing organic substances.

Cobalt exhibits several possible oxidation states $\left(\mathrm{Co}^{2+}, \mathrm{Co}^{3+}\right.$, and $\left.\mathrm{Co}^{4+}\right)$, including several types of coordinations (tetrahedral, pyramidal and octahedral). $\mathrm{Co}_{3} \mathrm{O}_{4}$ nanoparticles exhibit weak ferromagnetic behavior. $\mathrm{CoO}$ nanocrystals display superparamagnetism or weak ferromagnetism, whereas bulk $\mathrm{CoO}$ is antiferromagnetic.

$\mathrm{Co}_{3} \mathrm{O}_{4}$ is a magnetic $p$-type semiconductor. $\mathrm{Co}_{3} \mathrm{O}_{4}$ has a cubic spinel crystal structure in which the $\mathrm{Co}^{2+}$ ions occupy the tetrahedral sites and the $\mathrm{Co}^{3+}$ ions the octahedral sites. The $\mathrm{Co}^{3+}$ ions at the octahedral sites are diamagnetic in the octahedral crystal field. The $\mathrm{Co}^{2+}$ ions at the tetrahedral sites form an antiferromagnetic sublattice with a diamond structure. Consequently, cobalt oxides present a broad field for the creation of many frameworks in view of their stoichiometric and non-stoichiometric oxides, and mixed electronic valency of cobalt, and the presence of oxygen vacancies. This multi-electronic valence and rich coordinationis proper to cobalt oxides in comparison to other $3 \mathrm{~d}$ metal oxides. This provides cobalt the ability to be present in various spin states in its oxide forms: low, high, as well as intermediate spin. The cobalt spinel compounds can act as efficient catalysts in a lot of heterogeneous chemical processes. Among different synthesis techniques for cobalt oxide, the liquid-phase syntheses offer a good way and control for tailoring the structures, the compositions, and the morphological features of nanomaterials. The liquid-phase routes include the coprecipitation, the hydrolytic as well as the nonhydrolytic solgel processes, the hydrothermal or solvothermal methods, the template synthesis and microemulsion-based processes. Cobalt oxide nanoparticles with different morphologies such as spheres, rods, wires, cubes and porous structure have been reported. Sol-gel method has been widely used for the synthesis of $\mathrm{Co}_{3} \mathrm{O}_{4}$ nanoparticles where controlled fabrication of particles could be achieved by varying synthetic parameters such as reaction temperature, time and concentration of reagent $[7,8]$.

To clarify the role of $\mathrm{Co}_{3} \mathrm{O}_{4}$ catalyst in catalytic ozonation of nonylphenol ethoxylate, the $\mathrm{Co}_{3} \mathrm{O}_{4}-\mathrm{SiO}_{2}$ material was prepared and tested for the ozonation decomposition of NPE. Methods of X-ray diffraction(XRD), BrunauerEmmett-Teller (BET) surface area measurement, 
SEM images were used to characterise the catalyst.

\section{EXPERIMENTAL}

\section{Reagents}

All chemicals were analytical grade and used without further purification. Nonylphenol Ethoxylate (NPE), silica were purchased from Sigma-Aldrich. Cobalt (II) nitrate hexahydrate, urea, acetonitrile, ammonium acetate, ammonium chloride were from Merck.

\section{Synthesis of $\mathrm{Co}_{3} \mathrm{O}_{4}-\mathrm{SiO}_{2}$}

The material containing cobalt oxide supported on silica used as catalyst was prepare using sol-gel method [9]. In a typical experiment, $1 \mathrm{~g}$ of silica was dispersed in $500 \mathrm{~mL}$ of $10 \mathrm{mM}$ cobal tnitrate hexahydrate solution and sonicated for $3 \mathrm{~min}$. After that, $10 \mathrm{~g}$ of urea was added. The mixture was heated at $85^{\circ} \mathrm{C}$ and stirred for $6 \mathrm{~h}$. During the reaction, the color of the mixture changed from pink to violet indicating the formation of $\alpha$-cobalt hydroxide. The mixture was then cooled to room temperature, filtered using Munktell ${ }^{\circledR}$ paper, washed with Millipore ${ }^{\circledR}$ water several times and dried overnight in the oven. The obtained product was calcined in a muffle furnace (Lenton thermal ${ }^{\circledR}$ ) under air at $500^{\circ} \mathrm{C}$ for 3 hours at heating rate of $2 \% \mathrm{~min}$. The as-prepared product would be $\mathrm{Co}_{3} \mathrm{O}_{4}-\mathrm{SiO}_{2}$.

\section{Characterization of catalyst}

Structural analysis of the synthesized samples was carried out using powder X-ray diffraction on a Brucker AXS D8 diffractometer over the $2 \theta$ range of $10-90^{\circ}$ and the scan rate was of $1 \% \mathrm{~min}$. Copper was used as the target $(\mathrm{Cu}-\mathrm{K \alpha}$; $\lambda=1.5406 \AA$ ).
Morphological studies of the samples were carried out using Hitachi S-4800 II Field Emission Scanning Electron Microscope (SEM) with light element analysis using energy dispersive spectroscopy (EDS) operating at 10 $\mathrm{kV}$. Nitrogen adsorption-desorption measurement was also made at $77 \mathrm{~K}$ using BET method for specific surface area of the catalyst.

\section{Ozonation of NPE9 with $\mathrm{Co}_{3} \mathrm{O}_{4}-\mathrm{SiO}_{2}$}

Ozone was produced from dry air by use of Vina Ozone Generator model VN3 using Cold Plasma Technology. Ozone flow was measured by a ball flow rate meter. The concentration of ozone in aqueous solution was determined by UV-Vis spectrometer model T70+ manufactured by PG Instrument Ltd. at $258 \mathrm{~nm}$. Molar extinction coefficient is of $2950 \mathrm{~cm}^{-1} \mathrm{M}^{-1}$.

The flask containing NPE placed on a magnetic stirrer at 80rpm was used as ozonation reactor. The superflous ozone was adsorbed by activated carbon in aqueous absorption flask. The $\mathrm{pH}$ of the solution was adjusted by $\mathrm{HCl}$ or $\mathrm{NaOH}$. The Ozone flowrate was controlled by needle valves.

After ozonation, in order to avoid the influence of organic compounds in the mixture, residual ozone concentration was determined by indirect method in place of UV method: Ozone reacts with $\mathrm{KI}$ in solution to produce $\mathrm{I}_{2}$ which rapidly forms complex with $\mathrm{p}$-phenylenediamine for a UV-VIS absorption at $\lambda=540 \mathrm{~nm}$ and using Beer-Lambert equation $\mathrm{A}=\varepsilon .1$. C where $\mathrm{A}$ is the absorbance measured (unitless), $\varepsilon$ is the molar absorption coefficient $\left(\varepsilon=3300 \mathrm{~mol}^{-1} \mathrm{~cm}^{-}\right.$ $\left.{ }^{1}\right), \quad 1$ is the cuvette length $(\mathrm{cm}), \mathrm{C}$ is the concentration of ozone $(\mathrm{mole} / \mathrm{L})$ [9]. 


\section{Determination of NPEs concentration}

Determination of NPEs concentration was done by LC-MS of Agilent 1200 series with Quadrupole LC/MS 6120 detector, scan positive 100-1000 with fragmentor $70 \mathrm{~V}$, acetonitrile and $5 \mathrm{mM}$ Ammonium acetate (80:20, v/v) buffered. Millipore water was used as mobile phase solvent. The flowrate of the solvent was kept at $0.5 \mathrm{~mL} / \mathrm{min}$ and a XDB-C18 column of Agilent $(4.6 \times 150 \mathrm{~mm}, 5 \mu \mathrm{m})$ was used.

LC-MS confirmation and quantification of the concentration of NPEs were based on sum of each NPE with the number of ethoxylate group from 2 to 16. The chromatogram of NPEs was presented in Fig.1. and its mass spectrometry in Fig.2.

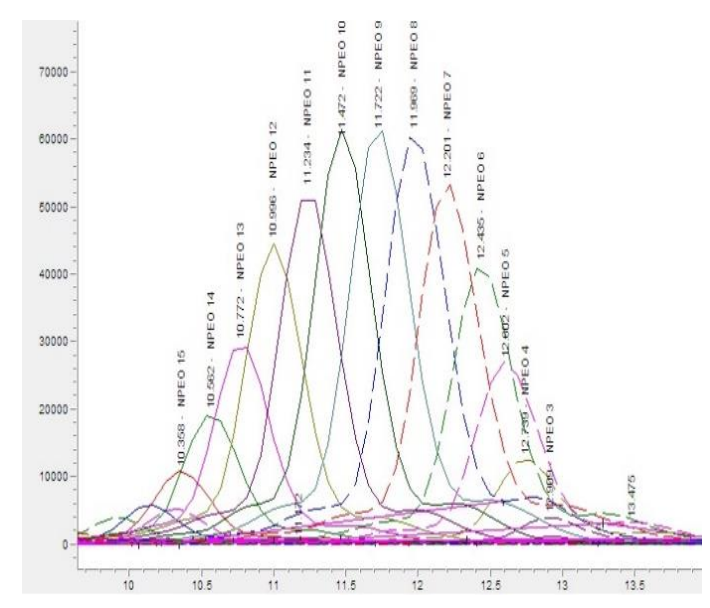

Figure 1. Chromatogram of NPEs

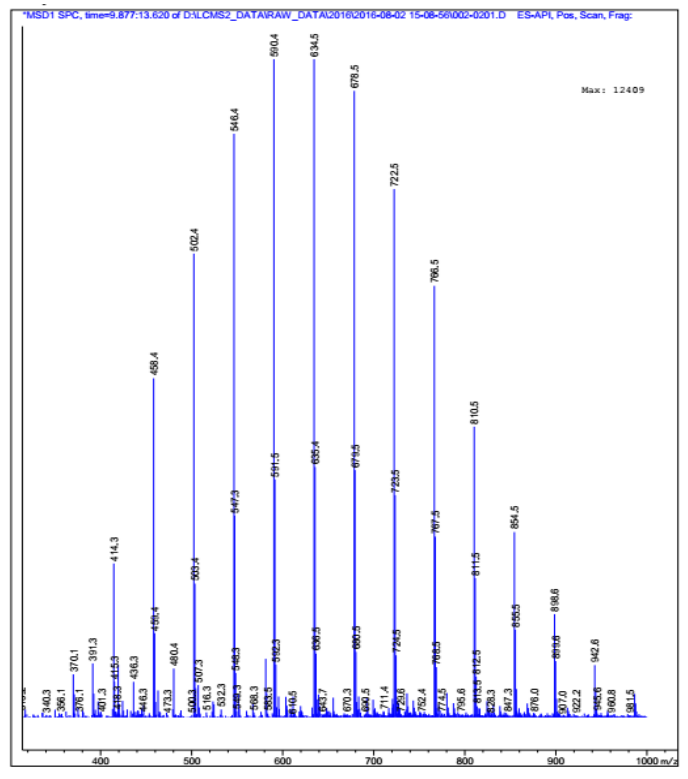

Figure 2. Mass spectrometry of NPEs

NPEs conversion yield (X\%) calculated by following equation:

$$
X \%=\frac{C_{0}-C}{C_{0}} \times 100 \%
$$

where $\mathrm{Co}, \mathrm{C}$ are subsequently NPES concentrations before and after treatment.

Mineralization of ozonation was investigated by measuring the mass of the $\mathrm{CO}_{2}$ gas in absorption of a $0.5 \mathrm{M} \mathrm{Ba}(\mathrm{OH})_{2}$ solution. The barium carbonate precipitate was dried at $110^{\circ} \mathrm{C}$ for an hour until constant weight. All the experiments were performed under ambient conditions in an environmentally controlled laboratory where the room temperature was $30 \pm$ $1{ }^{\circ} \mathrm{C}$. Noncatalytic ozonation (without $\mathrm{Co}_{3} \mathrm{O}_{4}$ $\mathrm{SiO}_{2}$ ) experiments were carried out in addition to catalytic ozonation (with $\mathrm{Co}_{3} \mathrm{O}_{4}-\mathrm{SiO}_{2}$ ) experiments for comparison.

\section{RESULTS AND DISCUSSION}

Characterization of $\mathrm{Co}_{3} \mathrm{O}_{4}-\mathrm{SiO}_{2}$ 
Cobalt oxide were obtained by calcination of cobalt hydroxide at $350^{\circ} \mathrm{C}$ with presence of $\mathrm{SiO}_{2}$ as support. The XRD diffractogram showed characteristic peak of $\mathrm{SiO}_{2}$ at $2 \theta=15.7^{\circ}, 25.3^{\circ}$. The diffraction peaks at $19.0^{\circ}, 31.3^{\circ}, 36.9^{\circ}$, $55.7^{\circ}$, and $65.2^{\circ}$ can be indexed to (111), (220), (311), (422), and (440) planes of $\mathrm{Co}_{3} \mathrm{O}_{4}$ crystal given by the standard data file (JCPDS file No. 42-1467), space group: Fd-3m (227); lattice constants: $\mathrm{a}=8.083 \mathrm{~A}^{\circ}$ ). Such sharp diffraction peaks indicate the well crystallization of $\mathrm{Co}_{3} \mathrm{O}_{4}$ (Fig.3). The particle size calculated from the line broadening of XRD peaks using Sherrer's formula $(\mathrm{d}=0.9 \lambda / \cos \beta)$ is of $50 \mathrm{~nm}$. Specific surface area of the catalyst measured by BET method is about $300 \mathrm{~m}^{2} / \mathrm{g}$.

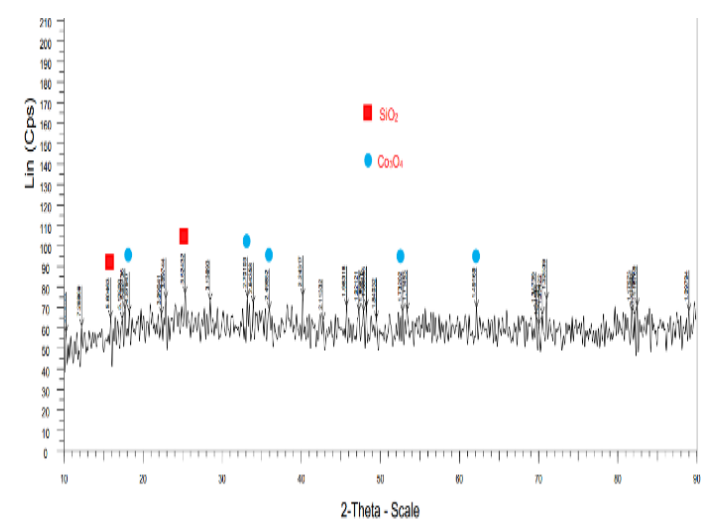

Figure 3. XRD pattern of $\mathrm{Co}_{3} \mathrm{O}_{4}-\mathrm{SiO}_{2}$

The SEM images of $\mathrm{Co}_{3} \mathrm{O}_{4}-\mathrm{SiO}_{2}$ in Fig.4 showed the nanorods morphology formed from silica spherical particles. It could be imagined the formation of (silica) - $\left(\mathrm{Co}_{3} \mathrm{O}_{4}\right)$ composite after the precipitation of $\mathrm{Co}(\mathrm{OH})_{3}$ on the silica surface. The aggregation of particles is also performed on the images. The shape of cobalt silica composite oxide looks like rod.

These short nanorods have average length of 200-300nm and diameter of 40-50nm
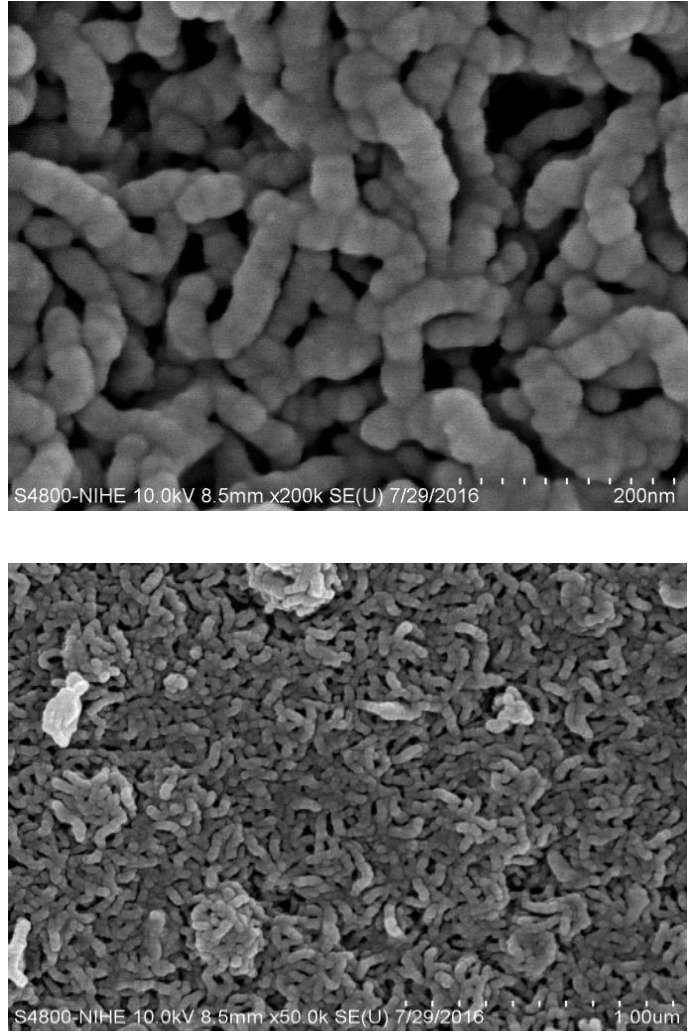

Figure 4. SEM images of $\mathrm{Co}_{3} \mathrm{O}_{4}-\mathrm{SiO}_{2}$

Effect of initial pH on NPE catalytic ozonation

In the NPE ozonation, the hydroxide ions plays an important role in initiating ozone decomposition which involves a series of reactions as follows $[9,10]$ :

$$
\begin{aligned}
& \mathrm{O}_{\mathrm{a}}+\mathrm{OH}^{-} \rightarrow \mathrm{O}_{2}+\mathrm{HO}_{2}^{-} \mathrm{k}=70 \mathrm{M}^{-1} \mathrm{~s}^{-1} \\
& \mathrm{O}_{\mathrm{a}}+\mathrm{HO}_{2}^{-} \rightarrow \mathrm{OH}+\mathrm{O}_{2}+\mathrm{O}_{2}^{*-} \mathrm{k}=2.8 \times 10^{6} \mathrm{M}^{-1} \mathrm{~S}^{-1} \\
& \mathrm{O}_{\mathrm{a}}+\mathrm{O}_{2}^{*-} \rightarrow \mathrm{O}_{\mathrm{a}}^{*-}+\mathrm{O}_{2} \mathrm{k}=1.6 \times 10^{9} \mathrm{M}^{-1} \mathrm{~s}^{-1} \\
& \mathrm{O}_{\mathrm{a}}^{*-}+\mathrm{H}^{+} \leftrightarrow \mathrm{HO}_{\mathrm{a}}^{*} \mathrm{k}=5 \times 10^{10} \mathrm{M}^{-1} \mathrm{~s}^{-1} \\
& \mathrm{HO}_{\mathrm{a}}^{*} \rightarrow \mathrm{OH}^{*}+\mathrm{O}_{2} \mathrm{k}=1.1-1.4 \times 10^{5} \mathrm{~s}^{-1} \\
& \mathrm{OH}^{*}+\mathrm{O}_{\mathrm{a}} \rightarrow \mathrm{HO}_{2}^{*}+\mathrm{O}_{2} \mathrm{k}=1.0 \times 10^{8}-3.0 \times 10^{9} \mathrm{M}^{-1} \mathrm{~s}^{-1}
\end{aligned}
$$


During the reaction as an oxidant the ozone molecule has selective electrophility for an interaction with amines, phenols and double bonds in aliphatic compounds. In appropriate medium, the ozone decomposition may also generate active secondary oxidants (mainly $\cdot \mathrm{O}^{2-}$ and $\cdot \mathrm{OH}$ radicals have higher potential and no selectivity) to oxidize molecules. Ozone is more selective than hydroxyl radical but the latter is stronger in reaction. Thus the reaction paths of ozone and organic compounds determined $\mathrm{pH}$ which changed the redox reactions also the amount of $\cdot \mathrm{OH}$ radical $[7,8]$.

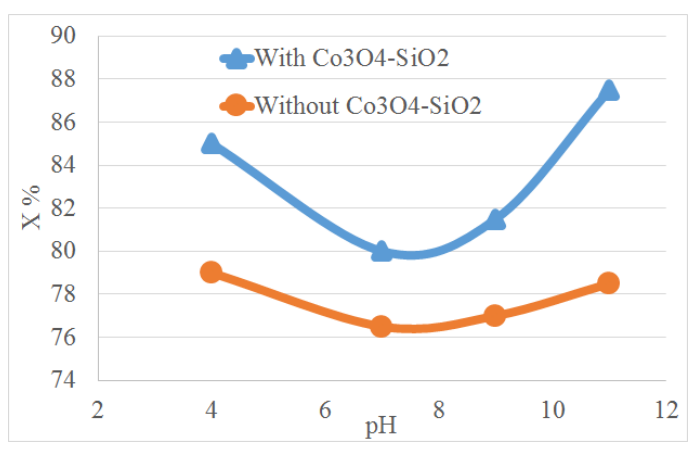

Figure 5. Effect of $\mathrm{pH}$ on NPEs ozonation yield $(\mathrm{t}=8$ $\min , \mathrm{V}_{\mathrm{O} 3}=1 \mathrm{~L} / \mathrm{min},\left[\mathrm{Co}_{3} \mathrm{O}_{4}-\mathrm{SiO}_{2}\right]=0.1 \mathrm{~g} / \mathrm{L},[\mathrm{NPEs}]_{\mathrm{o}}$ $=20 \mathrm{ppm}$ )

The plots in Fig.5. showed the apparent effect of initial $\mathrm{pH}$ on the ozonation efficiency. With $\mathrm{Co}_{3} \mathrm{O}_{4}$ as catalyst the ozonation efficiency was better than that without catalyst at any $\mathrm{pH}$. After 10 minutes, with catalyst, the NPE ozonation yield reached $88 \%$ at $\mathrm{pH}=11$ in comparison to $80 \%$ at $\mathrm{pH}=7$ and $85 \%$ at $\mathrm{pH}=4$. It is noted above that the mixed valency of cobalt atoms in $\mathrm{Co}_{3} \mathrm{O}_{4}$ catalyst was important for electron transport. The ability of electrons to transform between various oxidation states of the metallic ions determined the efficiencies of catalysts in redox reactions. This result is similar to our previous work concerning OMS-2 as catalyst in ozonation [3].

For the ozone decomposition on the surface of $\mathrm{Co}_{3} \mathrm{O}_{4}$ we propose following scheme:

$$
\begin{aligned}
& \mathrm{O}_{3}+\left[\mathrm{Co}^{2+}\right] \rightarrow \mathrm{O}_{2}+\mathrm{O}^{-}{ }_{\text {ads }}\left[\mathrm{Co}^{3+}\right] \\
& \mathrm{O}_{3}+\mathrm{O}^{-}{ }_{\text {ads }}\left[\mathrm{Co}^{3+}\right] \rightarrow \mathrm{O}_{2}+\mathrm{O}_{2}\left[\mathrm{Co}^{2+}\right] \\
& \mathrm{O}_{2}\left[\mathrm{Co}^{2+}\right] \rightarrow \mathrm{O}_{2}+\left[\mathrm{Co}^{4+}\right]
\end{aligned}
$$

The $\mathrm{Co}^{2+}$ ions could adsorb ozone so they accelerate ozone to react. In other words, the ozone decomposition could be favored by the presence of redox couple $\mathrm{Co}^{2+}, \mathrm{Co}^{3+}$ controlled by $\mathrm{pH}$ values.

\section{Effect of ozone flowrate}

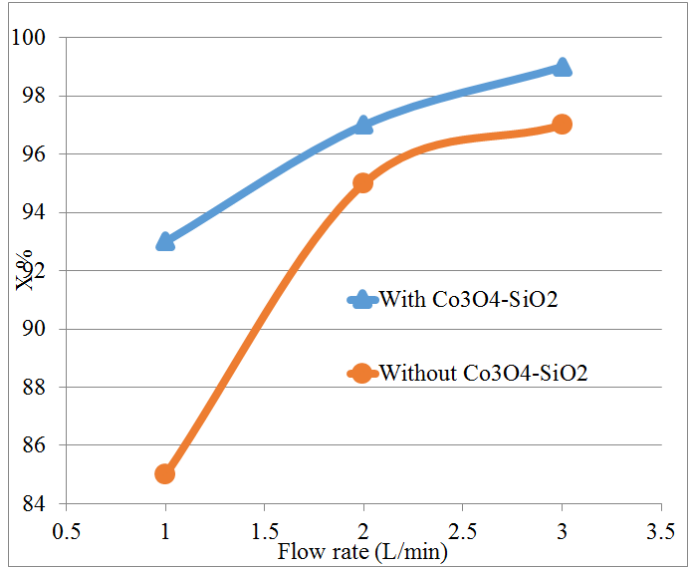

Figure 6. Effect of $\mathrm{O}_{3}$ flow rate on NPEs ozonation yield $\left(\mathrm{t}=6 \mathrm{~min},[\mathrm{NPEs}]=20 \mathrm{ppm},\left[\mathrm{Co}_{3} \mathrm{O}_{4}-\mathrm{SiO}_{2}\right]=\right.$ $0.1 \mathrm{~g} / \mathrm{L}, \mathrm{pH}=7)$

In ozonation the transport of ozone into the solution was very important. An increase of ozone flowrate could conduct a positive reponse to ozone content in solution. This was an acceleration for the reaction and an increase of ozonation efficiency. As shown in Fig.6, after 6 minutes at $\mathrm{O}_{3}$ flow rate of $3 \mathrm{~L} / \mathrm{min}$, the decomposition efficiency achieve 99\% with catalyst and $97 \%$ without catalysts. At small $\mathrm{O}_{3}$ 
flow rate of $1 \mathrm{~L} / \mathrm{min}$, the presence of $\mathrm{Co}_{3} \mathrm{O}_{4}-\mathrm{SiO}_{2}$ gave a much higher performance.

\section{Effect of initial NPE concentration}

The initial NPE concentration in rivers, streams, ponds, lakes, was strongly various in the range of 5-30ppm. It can be seen on Fig.7. that in the same condition, on increasing initial NPE concentration, the decomposition efficiency decreases.

With a small NPE concentration of 5ppm, it took only 2 minutes to decompose almost completely NPE in water. In the same condition, NPE concentration increased fourfold, the ability to treat only reached $65 \%$. It is noted that with an important content of NPE in medium, the rapid formation of foam caused great difficulty to the mass transfer in ozonation process.

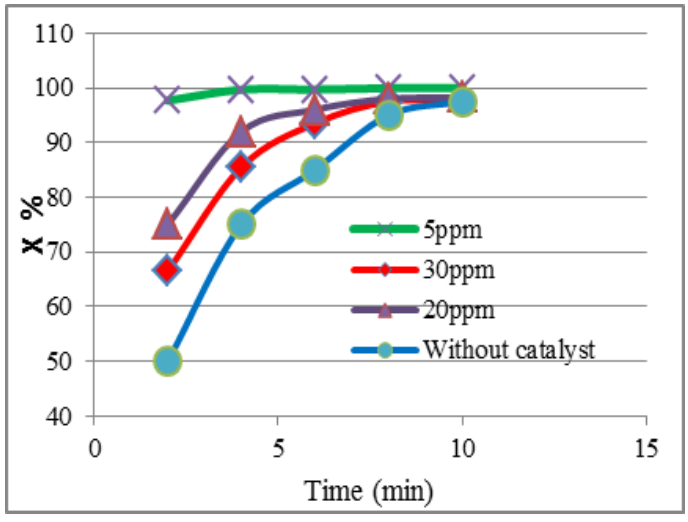

Figure 7. Effect of initial NPE concentration on ozonation yield $\left(\mathrm{V}_{\mathrm{O} 3}=1 \mathrm{~L} / \mathrm{min},\left[\mathrm{Co}_{3} \mathrm{O}_{4}-\mathrm{SiO}_{2}\right]=0.1\right.$ $\mathrm{g} / \mathrm{L}, \mathrm{pH}=7$ )

\section{Effect of catalyst content}

According to the above proposed possible mechanism of the catlytic ozonation the important role of active surface site $(*)$ were mentioned.

$$
\mathrm{O}_{3}+* \rightarrow \mathrm{O}_{2}+\mathrm{O} *
$$

$$
\begin{aligned}
& \mathrm{O}_{3}+\mathrm{O} * \rightarrow \mathrm{O}_{2} *+\mathrm{O}_{2} \\
& \mathrm{O}_{2} * \rightarrow \mathrm{O}_{2}+*
\end{aligned}
$$

First at all ozone molecules fulfilled a dissociated adsorption on active sites to create active oxygen atoms which then could form active oxidative peroxides or dioxygen radicals. Finally oxygen molecules were liberated along with active sites. In other words, the process involve transfer of electrons from supported metal to ozone molecules with the production of $\mathrm{O}_{2} \cdot$ and $\bullet \mathrm{OH}$ generation and further reaction with organic compound [9]. Increasing catalyst amount could give more surface sites for an increase of NPE decomposition yield.

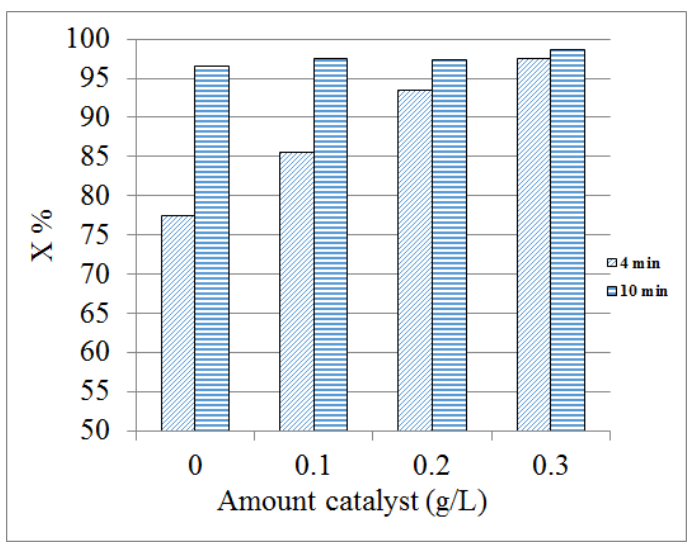

Figure 8. Effect of catalyst content on NPE ozonation yield $\left(\mathrm{V}_{\mathrm{O} 3}=1 \mathrm{~L} / \mathrm{min},[\mathrm{NPE}]=20 \mathrm{ppm}, \mathrm{pH}=7\right)$

Beside of active sites on $\mathrm{Co}_{3} \mathrm{O}_{4}$ it is worthy to mention about $\mathrm{SiO}_{2}$ which could only exchange cations. However $\mathrm{SiO}_{2}$ alone enhances the ozone decomposition from the collision, adsorption and energy effect.

The examination of the NPE adsorption on surface catalyst without ozonation was done at $\mathrm{pH}=7$ at various NPE initial concentration. 


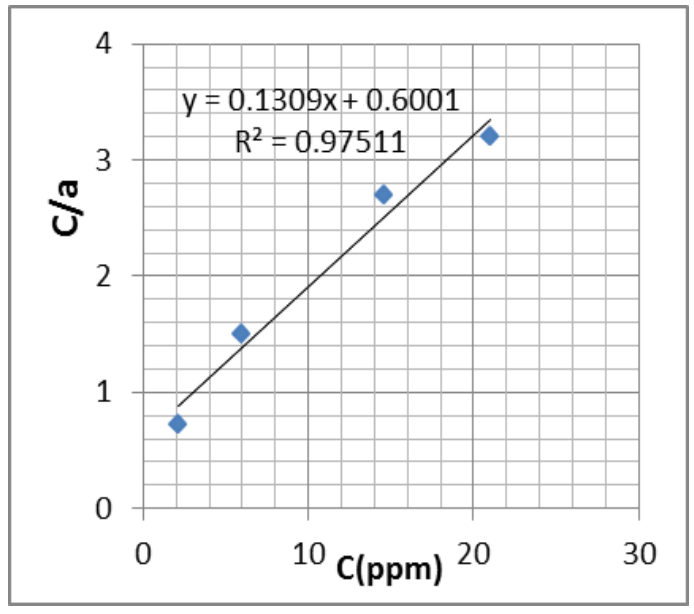

Figure 9. Langmuir adsorption isotherm of NPE on

$$
\mathrm{Co}_{3} \mathrm{O}_{4}-\mathrm{SiO}_{2}
$$

The Langmuir adsorption isotherm of NPE on $\mathrm{Co}_{3} \mathrm{O}_{4}-\mathrm{SiO}_{2}$ presented on Fig.9 showed the linear relation as equation $\mathrm{y}=0,13 \mathrm{x}+0,6\left(\mathrm{R}^{2}=\right.$ 0.975 ) where $C$ is equilibrium concentration after adsorption and $\mathrm{a}$ is adsorption capacity.

\section{Effect of ozonation time}

The efficiency of NPEs ozonation gradually increased with the increase of reaction time and showed in Fig. 10.

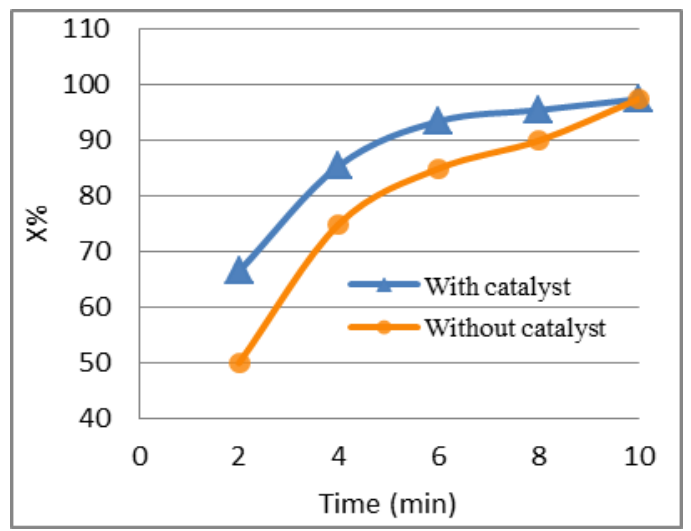

Figure 10. Effect of reaction time on NPEs ozonation yield $\left(\mathrm{V}_{\mathrm{O} 3}=1 \mathrm{~L} / \mathrm{min}, \mathrm{pH}=7,\left[\mathrm{SiO}_{2}-\mathrm{Co}_{3} \mathrm{O}_{4}\right]=0.1 \mathrm{~g} / \mathrm{L}\right.$, $\left.[\mathrm{NPE}]_{\mathrm{o}}=20 \mathrm{ppm}\right)$
Besides, during the NPEs ozonation decomposition, the control of physical properties of the aqueous solution was fulfilled. The conductivity was slightly increased from 2 to $6 \mu \mathrm{S} / \mathrm{cm}$ in 10 mins and $\mathrm{pH}$ was very slightly changed from 6.88 to 7.06 (Fig.11). It could be thought that the intermediate products of NPE9 ozonation process may a little contribute into the change of $\mathrm{H}^{+}$concentration as well as of the conductivity of the solution. The catalytic ozonation using cobalt oxides can increase the yield of ozonation just by creating more hydroxyl radicals on the surface of catalyst, that means the mechanisms of ozonation are nearly the same between catalytic ozonation and basic ozonation. Therefore the products of catalytic ozonation and ozonation would be the same, with a different yield. According to LC-MS analysis, it is interesting that there are no NP in the products. Preliminary investigation showed that more than $50 \%$ total carbon in NPE were mineralised after 60 mins of treatment. The study on the distribution of products in degradation ozonation has been continued.

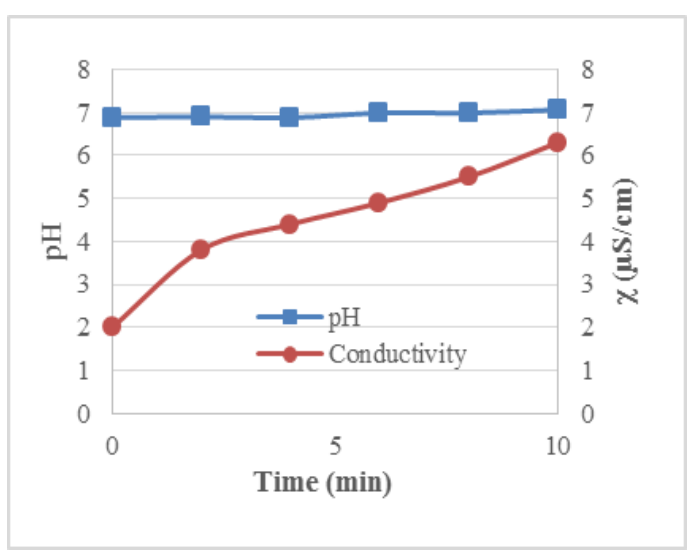

Figure 11. Conductivity and $\mathrm{pH}$ change in the NPEs ozonation degradation $\left(\mathrm{V}_{\mathrm{O} 3}=1 \mathrm{~L} / \mathrm{min}, \mathrm{pHo}=7\right.$, $\left.\left[\mathrm{SiO}_{2}-\mathrm{Co}_{3} \mathrm{O}_{4}\right]=0.1 \mathrm{~g} / \mathrm{L},[\mathrm{NPE}]_{\mathrm{o}}=20 \mathrm{ppm}\right)$. 


\section{CONCLUSION}

The degradation ozonation of NPE in the presence of $\mathrm{SiO}_{2}-\mathrm{Co}_{3} \mathrm{O}_{4}$ as heterogeneous catalyst was investigated. The best ozonation yield of $99 \%$ was achieved at temperature of $30^{\circ} \mathrm{C}$, during the reaction time of $10 \mathrm{mins}$, with an amount of catalyst about $0.1 \mathrm{~g} / \mathrm{L}$, at $\mathrm{pH}$ of the solution of 11 , using inlet ozone flow rate of 3 $\mathrm{L} / \mathrm{min}$, along with the initial NPEs concentration of $20 \mathrm{mg} / \mathrm{L}$. In this condition, more than $50 \%$ total carbon of NPE were mineralised after 60 mins of treatment. In conclusion, $\mathrm{SiO}_{2}-\mathrm{Co}_{3} \mathrm{O}_{4}$ catalytic ozonation is a reliable method that can be used as an addition stage in treatment processes to remove NPE from wastewater.

Acknowledgments: This work was funded by the CARE Laboratory and Ho Chi Minh City University of Technology under grant number TKTHH-2015-98.

\section{Xử lý nonyl phenol etoxylat trong nước bằng cách ozon hóa xúc tác với nano oxyt coban - silica}

- Trần Trương Trọng Trí

- Nguyễn Thị Mai My

- Nguyễn Ngọc Hạnh - Email: nnhanh@ hcmut.edu.vn

- Võ Hũu Thảo

Trường Đại Học Bách Khoa, ĐHQG-HCM

\section{TÓM TÁT}

Quá trình ozon hóa xúc tác và phân hủy chất hoạt động bè̀ mặt không ion NPE (nonylphenolethoxylate) dạng chất bẩn trong nuớc thải với sụ có mặt các hạt nano oxyt coban mang trên silica đã được khảo sát. Các tính chất đặc trung của oxyt coban mang trên silica được thục hiện bằng nhiễu xa tia $X$ và chup ảnh SEM. Anh hương của $p H$, nồng độ đầu NPE, thời gian ozon hóa và hàm luợng xúc tác trong quá trình ozon hóa cũng được nghiên cứu. Kết quả cho 
thấy NPE xủ lý bằng hệ xúc tác oxyt coban mang trên silica nhiều hơn là chỉ dùng ozon đơn thuần. Khoảng 99\% NPE được lấy đi trong vòng
10 phút ở $30^{\circ} \mathrm{C}$. Ngoài ra, hơn $50 \%$ carbon tổng trong NPE đã bị khoáng hóa trong điều kiện này.

Tù khóa: nonyl phenol ethoxylate, xúc tác, ozon hóa, $\mathrm{Co}_{3} \mathrm{O}_{4}$, khoáng hóa

\section{REFERENCES}

[1]. TERGITOL Tм NP-9 Surfactant Material Safety Data Sheet, 2009, The Dow Chemical Company

[2]. TERGITOL ${ }^{\mathrm{TM}}$ NP-40 Surfactant Material Safety Data Sheet, 2003, The Dow Chemical Company

[3]. T.T. Tran-Truong, M.M.T. Nguyen, T. VoHuu, K. Nguyen, D.T. Nguyen, H. Nguyen-Ngoc, Catalytic ozonation of nonyl phenol ethoxylates in water by octahedral molecular sieve (OMS-2), $5^{\text {th }}$ World Conference on Applied Sciences, Engineering \& Technology 2016, HCMUT, Vietnam (2016)

[4]. D. Xavier, R. Wilson, S. Laura S, A.M. Josep, A. Pilar, Soil pollution by nonylphenol and nonylphenolethoxylates and their effects to plants and invertebrates, J .Soils Sediments, 9, 555-567 (2009)

[5]. Y. Yoshida, A. Ito, M. Murakami, T. Murakami, et al, Determination of nonylphenolethoxylates and octylphenolethoxylates in environmental samples using ${ }^{13} \mathrm{C}$-labeled surrogate compounds, J. Air Waste Manage Assoc., 57(10), 1164-71 (2007)

[6]. Ambreen, I. Munawar, B.A. Ijaz, A.Z. Muhammad, et al., Synthesis, characterization and photocatalytic activity of $\mathrm{ZnO}$ flower and pseudo-sphere:
Nonylphenolethoxylate degradation under UV and solar irradiation, Journal of Alloys and Compounds, 678, 126-136 (2016).

[7]. I. Munawar, B.A. Ijaz, Gamma radiation $/ \mathrm{H}_{2} \mathrm{O}_{2}$ treatment of a nonylphenolethoxylates: Degradation, cytotoxicity, and mutagenicity evaluation, Journal of Hazardous Materials, 299, 351360 (2015).

[8]. A. .Sambandam, L. Gang-Juan, Y. ChuanKai, A. Muthupandian, et al, Sonochemical synthesis of $\mathrm{Bi}_{2} \mathrm{CuO}_{4}$ nanoparticles for catalytic degradation of nonylphenolethoxylate, Chemical Engineering Journal, 183, 46-52 (2012)

[9]. K. Ikehata and M.G. El-Din, Degradation of recalcitrant surfactants in wastewater by ozonation and advanced oxidation processes: A review, Ozone: Science \& Engineering, 26, 327-343 (2004)

[10].B.K. Hordern, M. Ziolek, J. Nawrocki, Catalytic ozonation and methods of enhancing molecular ozone reactions in water treatment, Applied Catalysis B Environment, 46, 633-649 (2003). 